\title{
Enantioselective Synthesis of Cyclic Dipeptides by Iridium-Catalyzed Hydrogenation
}

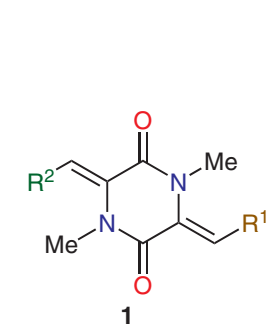

$\mathrm{R}^{1}=\mathrm{Alk}, \mathrm{Ar}, \mathrm{HetAr}$

$\mathrm{R}^{2}=\mathrm{Alk}, \mathrm{Ar}, \mathrm{Het} \mathrm{Ar}$
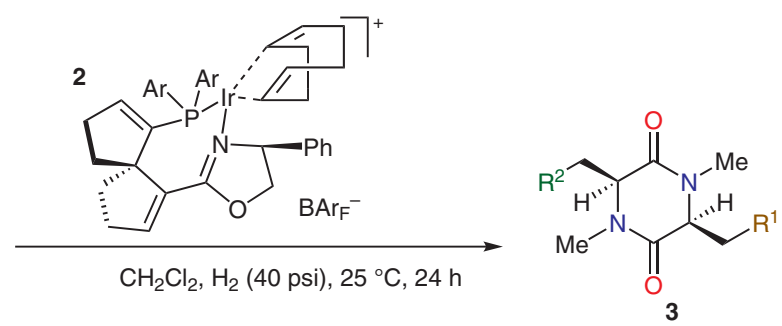

-27 examples

- cis only

- up to $98 \%$ ee

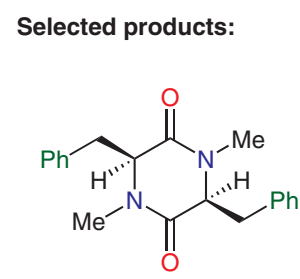

3a: $98 \%$ yield, $94 \%$ ee

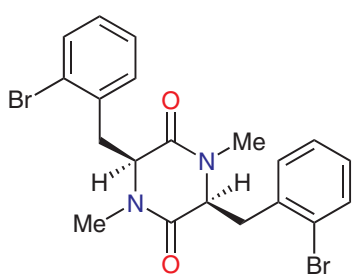

3b: $99 \%$ yield, $94 \%$ ee

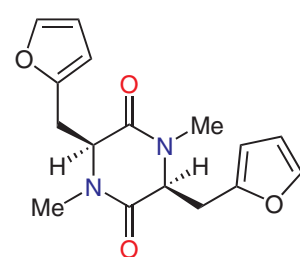

3c: $85 \%$ yield, $95 \%$ ee

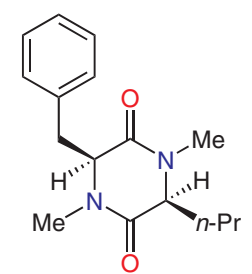

3d: $99 \%$ yield, $64 \%$ ee<smiles>CC[C@H]1C(=O)N(C)[C@H](CC)C(=O)N1C</smiles>

3e: $99 \%$ yield, $70 \%$ ee
Significance: The 2,5-dioxopiperazine motif, also known as a cyclic dipeptide, is found in compounds possessing biological activity, such as retosiban and fumitremorgin C (see first Review below). In addition, the motif has found utility in asymmetric synthesis as a chiral auxiliary or organocatalyst (see second Review below; C. Becker et al. Eur. J. Org. Chem. 2005, 1497). The synthesis of the ring system is usually accomplished by careful cyclization of protected acyclic peptide precursors. Other methods exist, including asymmetric alkylation of 2,5-diketopiperazines and, to a limited degree, asymmetric reduction of compounds similar to 1 by cobalt catalysis in the total synthesis of an alkaloid (S. Takeuchi et al. Heterocycles 1990, 31, 2073).
Comment: In the current method, the asymmetric reduction of compounds $\mathbf{1}$ to give dioxopiperazines 3 in high yields with ee values of up to $98 \%$ and exclusive formation of the cis diastereomer. The optimal catalyst [SpinPHOX/Ir(I)] was identified by screening a series of ligands. The scope of the reduction is exemplified by products $3 \mathbf{a}-\mathbf{e}$. A mechanism that rationalizes the high ee values observed is proposed in which two $\mathrm{C}=\mathrm{C}$ double bonds of the substrate are hydrogenated successively while bound to the iridium center.

Reviews: 1. A. D. Borthwick Chem. Rev. 2012, 112, 3641-3716; 2. E. A. Colby Davie, S. M. Mennen, Y. Xu, S. J. Miller Chem. Rev. 2007, 107, 5759-5812. 